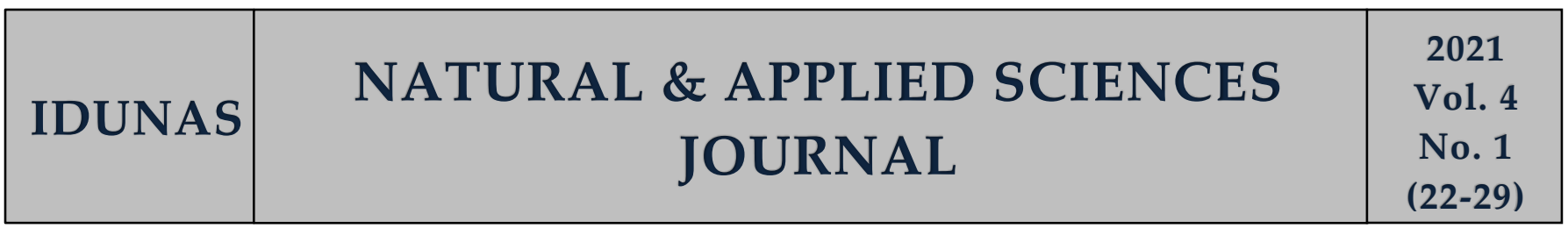

\title{
Experimental Modal Analysis and Structural Health Monitoring of the Double Curvature Deriner Arch Dam
}

\author{
Research Article

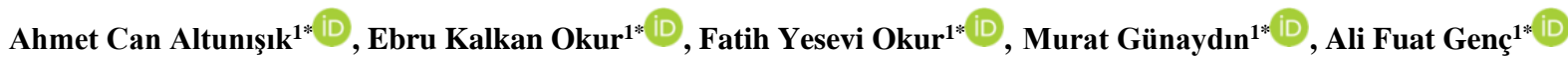 \\ ${ }^{l}$ Department of Civil Engineering, Karadeniz Technical University, Trabzon, Turkey. \\ Author E-mails \\ ahmetcan@ktu.edu.tr \\ ebrukalkan@ktu.edu.tr \\ yesevi@ktu.edu.tr \\ muratgunaydin@ktu.edu.tr \\ af.genc@ktu.edu.tr \\ *Correspondance to: Ahmet Can Altunışık, Department of Civil Engineering, Karadeniz Technical University, Trabzon, Turkey. \\ DOI: $10.38061 /$ idunas.851853
}

Received: 01.01.2021; Accepted: 06.03.2021

\section{Abstract}

Arch dams have delicate sections thanks to their curvature. The fact that these dams are large, costly and construction takes many years increases the importance of the structure. Mistakes and / or accidents that may occur during the construction of such structures may occur major loss of life and property. Considering the volumes, masses and slenderness of arch dams, they can be significantly affected by dynamic forces such as changing water pressure, temperature, wind and earthquakes. The level of these effects and to what extent they affect the dam can be determined by the analysis to be made to finite element model created by computer. Since Finite Element Analysis is based on certain assumptions, the results obtained should be compared and / or verified with the results obtained by experimental methods. One of the most suitable methods preferred in many engineering structures is the experimental modal analysis method. Within the scope of the study, experimental vibration tests were carried out in order to evaluate and determine the structural behavior of the double curvature Deriner Arch Dam, which has a body height of $249 \mathrm{~m}$ and a crest length of $720 \mathrm{~m}$. Experimental measurements were carried out with accelerometers placed in appropriate places in order to obtain the mode shapes of the dam. The dynamic characteristics of the dam were determined using OMA software. The first seven natural frequencies of the Deriner arch dam were obtained in the range $1.60-4.10 \mathrm{~Hz}$. As a result of the negotiations with the DSI 26th Regional Directorate, the acceleration data obtained from the existing accelerometer system of the dam was instantly taken and a continuous monitoring process was initiated. This data was transferred to the web-based monitoring site and a structural condition monitoring platform was created.

Keywords: Deriner arch dam, Experimental modal analysis, Structural health monitoring. 


\section{INTRODUCTION}

Historical buildings, bridges, high-rise buildings and dams are important engineering structures of strategic importance. These structures have different features with their usage areas, aesthetic appearance, their surroundings and their location, and there are many different examples in our country. Most of these structures, which have many variable parameters such as different material properties, construction techniques and ground properties from the first periods, have survived despite changing conditions and are still operating, and some of them are waiting to succumb to time and disappear.

Our country is home to many structures in terms of building diversity and has various dam structures built in order to process many rivers and streams it has without harming the nature and to meet the energy needs of humanity. For the dam planned to be built, it is necessary to determine the most suitable dam type (weight, earth fill, rock fill, clay core, arch braces, concrete front face, roller compacted and arch dams etc.) by considering regional characteristics, purpose of use and economic situation.

Considering the volumes, heavy masses and slenderness of arch dams, they can be significantly affected by dynamic forces such as changing water pressure, temperature, wind and earthquakes. The behavior of the structure under these dynamic effects is determined depending on the dynamic characteristics defined as natural frequency, mode shape and damping ratio. Today, dynamic characteristics are determined analytically as a result of modal (free vibration) analysis of finite element models created according to element sizes, material properties and boundary conditions determined by considering the project data of linear structures. However, the parameters taken into account during the analysis may have changed due to reasons such as the loss of strength of the structure material over time, construction errors during the construction of the building, cracks, fatigue and support collapses caused by the different loads to which the building is exposed, and the dynamic characteristics of the building may have moved away from the project values over time. Therefore, it is thought that incorrect analysis results can be obtained by using analytically determined dynamic characteristics in determining the behavior of structures under earthquake and continuous dynamic loads. This idea has been emphasized in studies by many researchers [1-8]. Therefore, the dynamic characteristics of the structure should be determined by experimental methods as well as analytical methods. Since the Experimental Modal Analysis method is applied directly to the structure, the dynamic characteristics obtained reflect the current state of the structure.

Engineering structures continue to be used despite aging and deterioration far beyond their design life. Conventional control and monitoring techniques performed on these structures may produce inconsistent results. Besides, traditional inspection methods are very labor and time consuming. Therefore, new structural health monitoring systems should be developed that are automatic, highly sensitive, sensitive to minimal changes and cost effective [9]. Structural health monitoring is a continuous system description of a physical or parametric model of the building using time-dependent data [10]. Improvements in sensor placement and computational modeling allow important steps to be taken in the field of Structural Health Monitoring in the near future. A commonly used Structural Health Monitoring strategy is to perform a vibration analysis in which an intact (initial) model of the structure is compared with vibration response data collected from the physical structure. Differences between model estimates and monitoring data can be interpreted as structural damage [11]. In recent years, the management and security control of dams are based on automatic monitoring by used advanced technology. This situation allows the evaluation of the structural condition that changes over time and intervention in the structure in case of emergency in engineering structures of great importance [12-16].

In this study, it was aimed to develop a Web-based Structural Health Monitoring Portal to evaluate the structural condition of Deriner Arch Dam and to monitor its current status. Experimental modal analysis 
test of Deriner Arch Dam, which is Turkey's highest dam is made. In addition, data from the existing accelerometer system in Deriner Dam has been transferred to the online Structural Health Monitoring platform. Thus, instant monitoring and storage of data is provided.

\section{EXPERIMANTAL MODAL ANALYSIS OF DERINER ARCH DAM}

Deriner Dam is a double curvature concrete arch dam and was built on the Coruh River. The body height from the foundation is $249.00 \mathrm{~m}$ and the crest length is $720 \mathrm{~m}$. The dam construction, which started in 1998, was completed and in 2012 the water started to be kept. Experimental vibration tests have begun to be carried out in order to evaluate and determine the structural behavior of Deriner Arch Dam, which continues to produce electricity at full capacity, over the years and the structural behaviors it will show in the future. In the tests, cable accelerometers with single axis type B\&K 8340 and a sensitivity of $10 \mathrm{~V} / \mathrm{g}$ were used. The signals from the accelerometers were collected in a B\&K 3560 type 17-channel data acquisition unit and transferred to PULSE [17] software. Dynamic characteristics were determined using OMA [18] software.

Ambient vibration tests were carried out under the effect of wind and water pressure in Deriner Arch Dam. The first measurement on Deriner Dam was carried out on 12 June 2019 with accelerometers placed at the crest level. Photographs of the experimental measurements made in the Deriner Arch Dam are given in Figure 1.

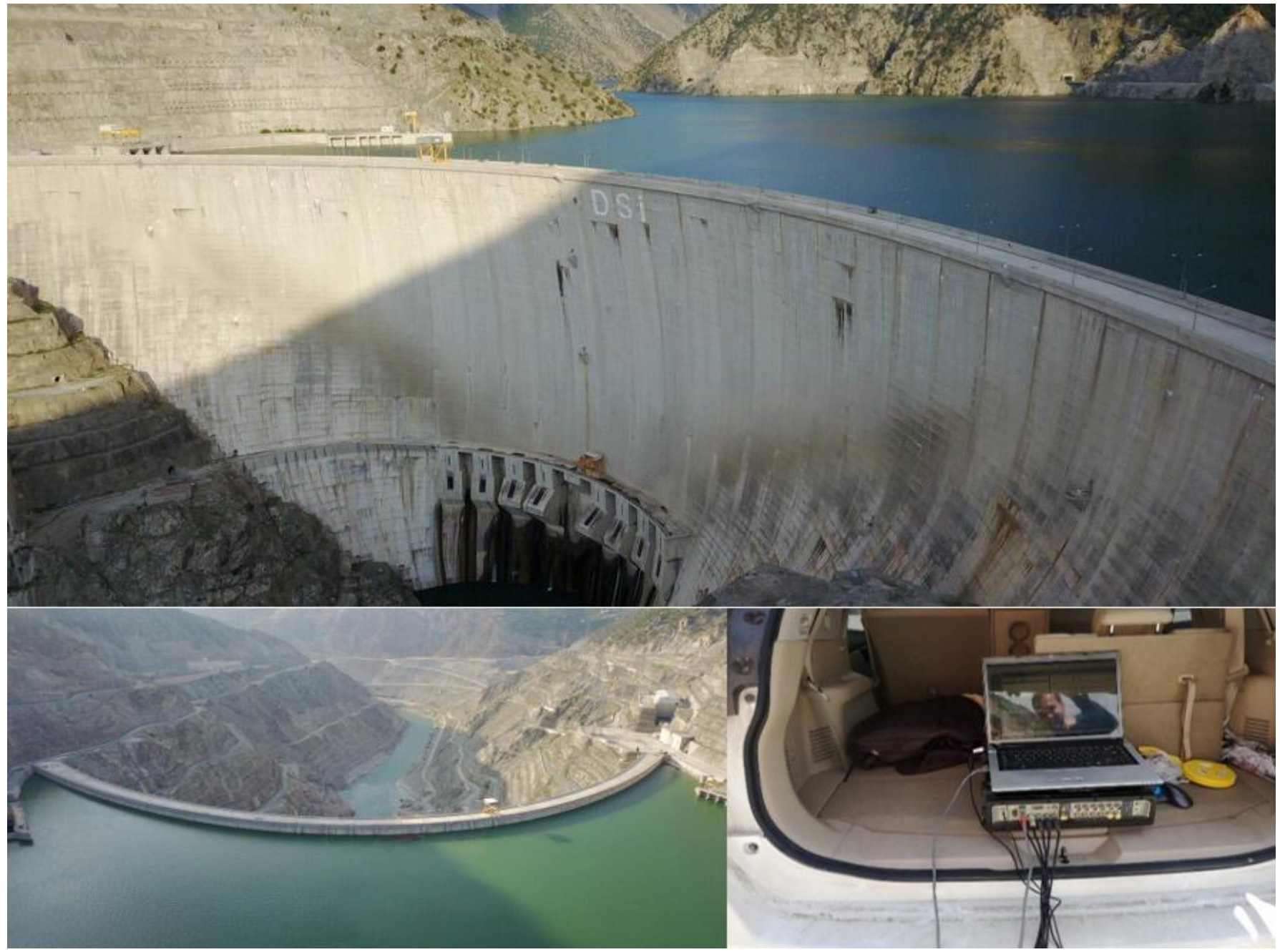

Figure 1. Some photos of the experimental measurements carried out in Deriner Arch Dam. 
During the test, accelerometers were placed upstream-downstream of the dam crest. Because of the limited number of accelerometers and cable lengths, experimental measurements were taken by creating three different setup (Figure 2). Each setup was carried out by taking measurements with reference within itself (Figure 3). The distance between the accelerometers was determined as $45 \mathrm{~m}$ and 9 accelerometers were used in setup 1 and 2, and 7 accelerometers were used in setup 3. At each measurement, measurements were taken for 30 minutes and signals were collected.

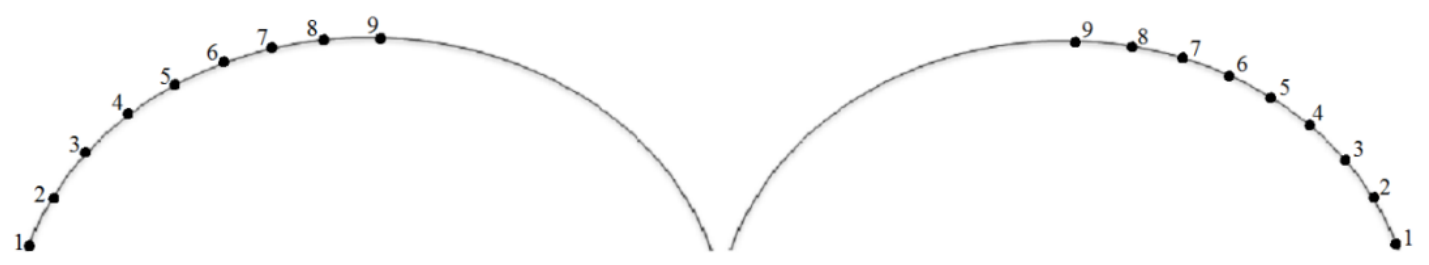

a) Setup-1

b) Setup-2

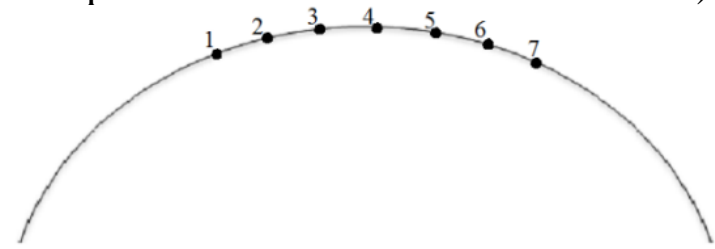

c) Setup-3

Figure 2. Schematic representation of the measurements made in the Deriner Arch Dam.
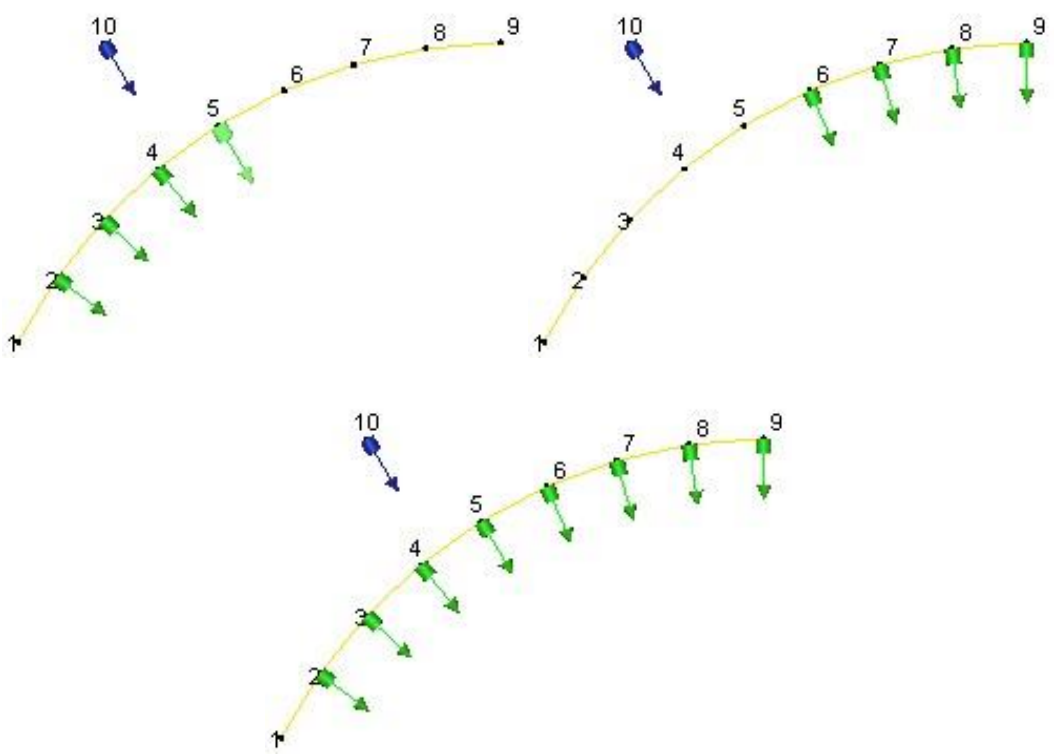

a) Setup-1 

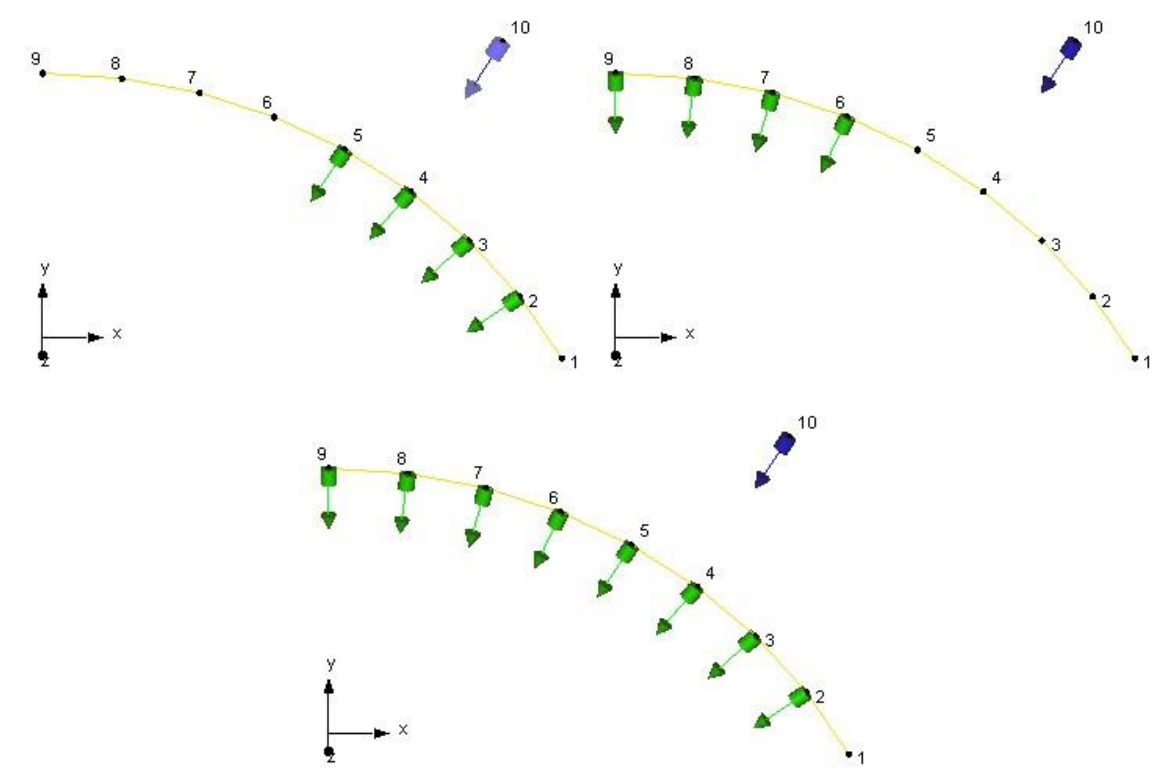

b) Setup-2

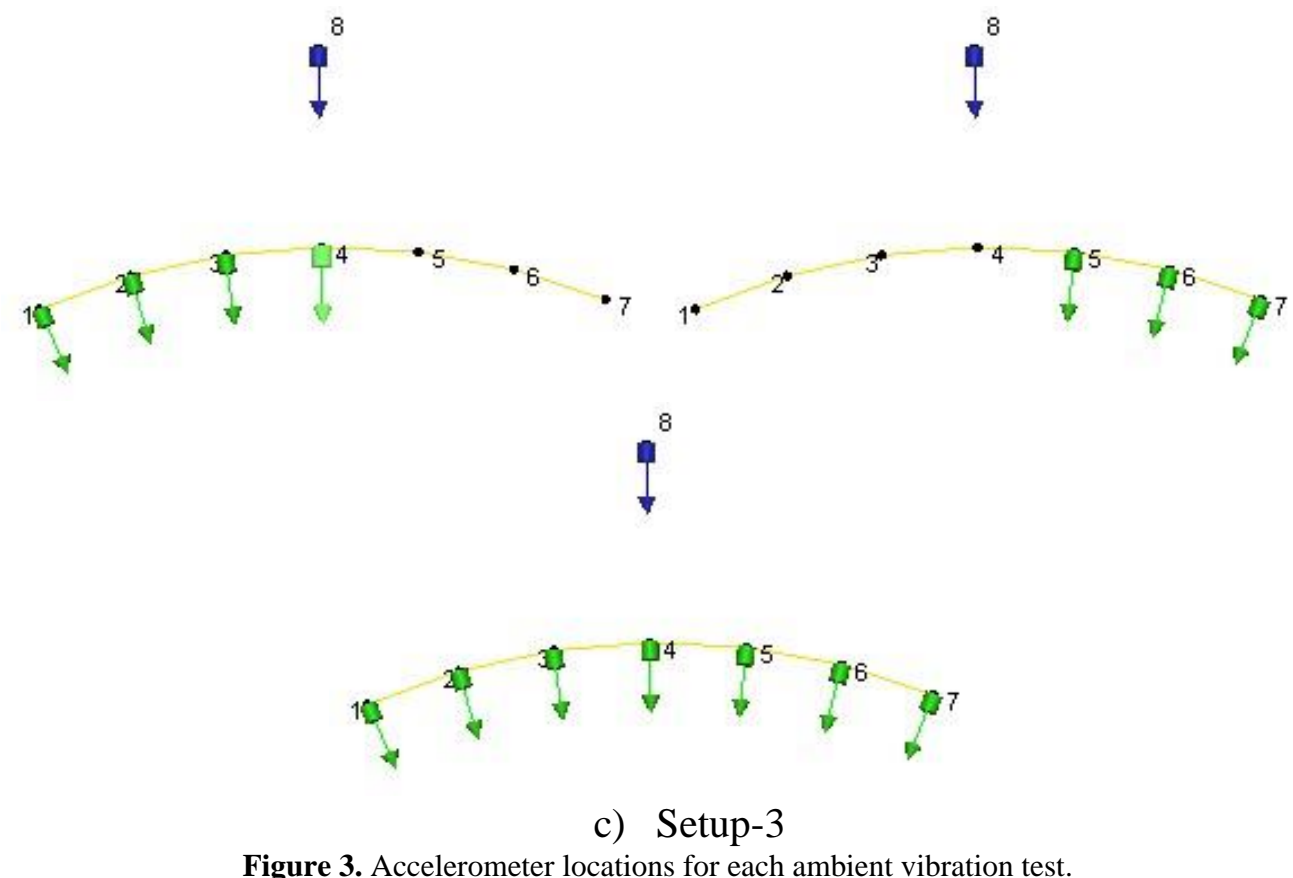

Figure 3. Accelerometer locations for each ambient vibration test.

Figure 4 shows the diagram obtained in the frequency domain according to the Enhanced Frequency Domain Decomposition (EFDD) methods from the ambient vibration tests of the Deriner dam. Table 1 shows the frequency values obtained from setup- 1 and setup-3 of the Deriner Arch Dam's measurement dated 12/06/2019. 


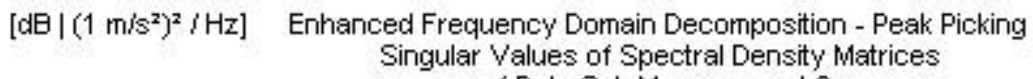
Singular Values of Spectral Density Matrices

of Data Set: Measurement 2

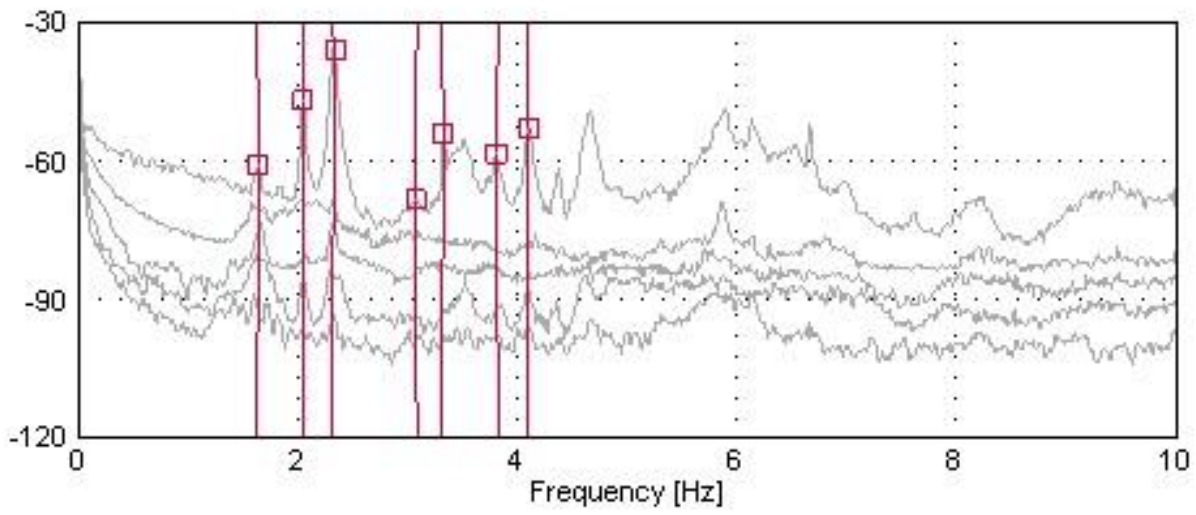

Figure 4. Singular value of spectral density matrices of Deriner Arch Dam.

Table 1. Frequency values obtained from setup-1 and setup-3 of Deriner Arch Dam's measurements dated 12/06/2019.

\begin{tabular}{|c|cc|}
\hline \hline \multirow{2}{*}{ Mode No } & \multicolumn{2}{|c|}{ Frequency Values (Hz) } \\
\cline { 2 - 3 } & Setup-1 & Setup-3 \\
\hline \hline 1 & 1.638 & 1.638 \\
\hline 2 & 2.052 & 2.158 \\
\hline 3 & 2.310 & 2.286 \\
\hline 4 & 3.090 & 3.057 \\
\hline 5 & 3.322 & 3.498 \\
\hline 6 & 3.831 & 3.950 \\
\hline 7 & 4.105 & 4.098 \\
\hline
\end{tabular}

\section{STRUCTURAL HEALTH MONITORING OF DERINER ARCH DAM}

Deriner Arch Dam currently has systems for monitoring structural health. However, existing measuring instruments allow only certain and insufficient data to be received. 5 accelerometers in Deriner Arch Dam record only 4sec data between 00:00:00 and 00:00:00 every night. Short-term measurement records are not sufficient for processing data and obtaining frequency values. For this reason, it was ensured that data from the current accelerometer system was continuously received and recorded 24/7 and transferred to the Structural Health Monitoring Portal prepared on a web-based. Figure 5 shows the interface of the website prepared.

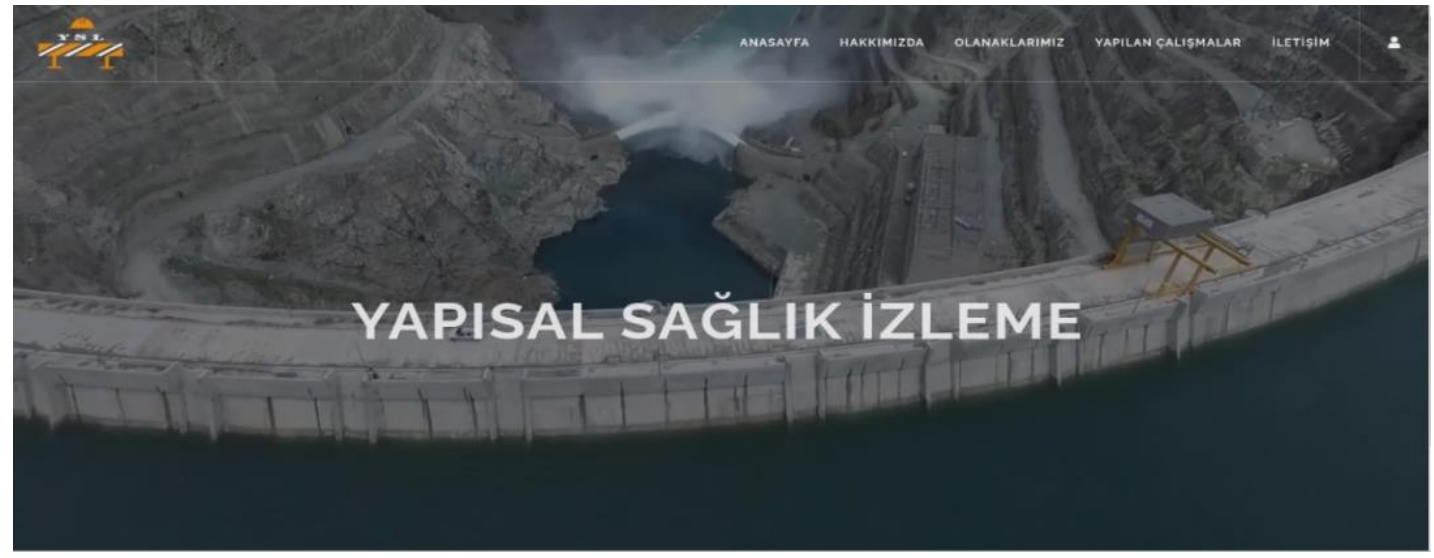

Figure 5. Structural Health Monitoring website. 
With this portal, it was ensured that the signal data received from the accelerometer can be monitored online and accessed on the desired date. Figure 6 shows the page where instantaneous acceleration data of Deriner arch Dam are obtained.

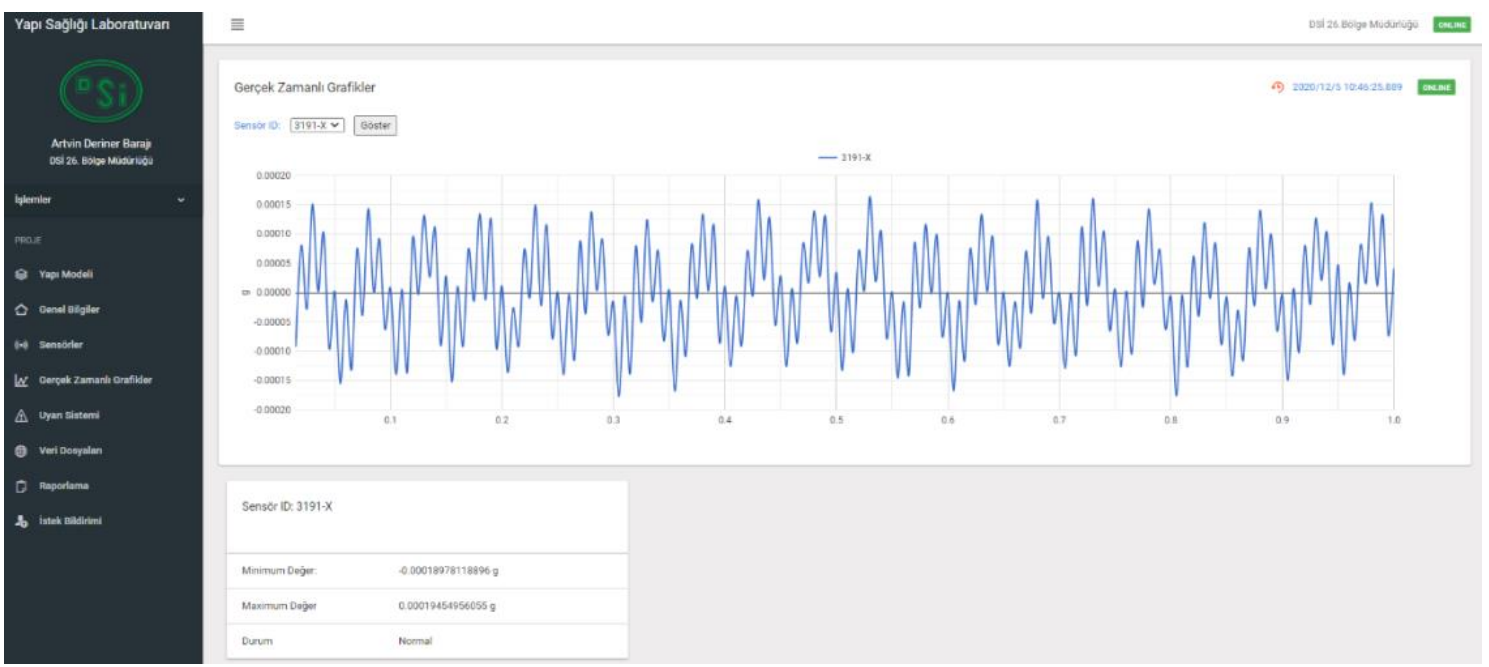

Figure 6. Instant acceleration data of Deriner Arch Dam.

\section{CONCLUSION}

In this article, studies carried out to evaluate the structural condition of Deriner Arch Dam and to continuously monitor its current situation are included. Experimental modal analysis tests of the double curvature Deriner Arch Dam built on the Coruh River were conducted. As a result of the experimental measurements, the frequency values of the first seven modes expressing the current state of the dam were obtained between $1.6 \mathrm{~Hz}$ and $4.1 \mathrm{~Hz}$. Due to insufficient data collection in the existing structural health monitoring system in the dam, the acceleration data of the dam can be instantly transferred to the Webbased Structural Health Monitoring Portal prepared by improving the existing system. Acceleration data of the dam can be monitored and stored instantly with this web-based portal.

\section{ACKNOWLEDGMENTS}

We would like to thank the General Directorate of State Hydraulic Works (DSI in Turkish acronym) and the 26th Regional Directorate for granting the necessary permits for the experimental studies carried out at Artvin Deriner Dam.

\section{REFERENCES}

1. Chuntavan, C. (1993). Structural identification of steel stringer bridges for condition assessment, Doctoral Thesis, University of Cincinnati, Cincinnati, USA.

2. Womack, K. C., Halling, M. W. (1999). Forced vibration testing of the I-15 south temple bridge, Project Final Report, Report No: UT-99.15, Department of Civil and Environmental
Engineering, Utah State University, Logan, Utah, USA.

3. Achter, J. L. (2000). Full-scale bridge bent condition assessment using forced-vibration testing, Master Thesis, Utah State University, Logan, Utah. 
4. Inaudi, D., Casanova, N., Vurpillot, S., Glisic, B., Kronenberg, P., Lloret, S. (2000). Bridge deformation monitoring during enlargement and refurbishment works under traffic conditions, International Association for Bridge and Structural Engineering, IABSE, 16th Congress, Luzern, Switzerland.

5. Halling, M. W., Muhammad, I., Womack, K. C. (2001) Dynamic field testing for condition assessment bridge bents, Journal of Structural Engineering, ASCE, 127(2), 161-167.

6. Zhao, J., DeWolf, J. T. (2002) Dynamic monitoring of steel girder highway bridge, Journal of Bridge Engineering, ASCE, 7(6), 350-356.

7. Brownjohn, J. M. W., Moyo, P., Omenzetter, P., Lu, Y. (2003). Assessment of highway bridge upgrading by dynamic testing and finite-element model updating, Journal of Bridge Engineering, ASCE, 8(3), 162-172.

8. Kim, J. T., Stubbs, N. (2003). Nondestructive crack detection algorithm for full-scale bridges, Journal of Structural Engineering, ASCE, 129(10), 1358-1366.

9. Reagen, D., Sabato, A., Christopher N. (2017). Unmanned aerial vehicle acquisition of threedimensional digital image correlation measurements for structural health monitoring of bridges, Nondestructive Characterization and Monitoring of Advanced Materials, Aerospace and Civil Infrastructure, 10.1117/12.2259985.

10. Brownjohn, J. M. W. (2009) Structural healt monitoring of civil infrastructure, Mathematical, Physicaland Engineering Sciences, 365, 589-622.

11. Buren, K. V., Reilly J., Neal K., Edwards H., Hemez F. (2017). Guaranteeing robustness of structural condition monitoring to environmental variability, Journal of Sound and Vibration, 386, 134-148.

12. Pereira, S., Magalhaes, F., Cunha, A., Gomes, J., Lemos, J. V. (2019). Installation and results from the first 18 months of operation of the dynamic monitoring system of Baixo Sabor Arch Dam, 6th International Symposium on Life-Cycle Civil Engineering (IALCCE), 1167-1173, Ghent, Belgium.

13. Oliveira, S., Alegre, A. (2019). Seismic and structural health monitoring of dams in Portugal, Seismic Structural Health Monitoring: From Theory to Successful Applications, Springer International Publishing AG, 87-113.

14. Oliveira, S., Alegre, A. (2020). Seismic and structural health monitoring of Cabril Dam. Software development for informed management, Journal of Civil Structural Health Monitoring, 10(5), 913-925.

15. Liseikin, A. V., Seleznev, V. S., Adilov, Z. A. (2020). Monitoring of the natural frequencies of Chirkey Arch Dam, Magazine of Civil Engineering, 96(4), 15-26.

16. Hsu, T. Y., Valentino, A., Liseikin, A., Krechetov, D., Chen, C. C., Lin, T. K., Wang, R. Z., Chang, K. C., Seleznev, V. (2020). Continuous structural health monitoring of the SayanoShushenskaya Dam using off-site seismic station data accounting for environmental effects, Measurement Science and Technology, 31(1), 015801.

17. PULSE, (2006). Analyzers and Solutions, Release 11.2. Bruel and Kjaer, Sound and Vibration Measurement A/S, Denmark.

18. OMA, (2006). Release 4.0, Computer Software. Structural Vibration Solution, Aalborg, Denmark. 